\title{
Nonuniformity of diffusing capacity from small alveolar gas samples is increased in smokers
}

\author{
DJ Cotton MD FRCPC, JT Mink BSc, BL Graham PhD \\ Division of Respiratory Medicine, Department of Medicine, Royal University Hospital, \\ University of Saskatchewan, Saskatoon, Saskatchewan
}

\begin{abstract}
DJ Cotton, JT Mink, BL Graham. Nonuniformity of diffusing capacity from small alveolar gas samples is increased in smokers. Can Respir J 1998;5(2):101-108.
\end{abstract}

BACKGROUND: Although centrilobular emphysema, and small airway, interstitial and alveoli inflammation can be detected pathologically in the lungs of smokers with relatively well preserved lung function, these changes are difficult to assess using available physiological tests. Because submaximal single breath washout $\left(\mathrm{SBW}_{\mathrm{SM}}\right)$ manoeuvres improve the detection of abnormalities in ventilation inhomogeneity in the lung periphery in smokers compared with traditional vital capacity manoeuvres, $\mathrm{SBW}_{\mathrm{SM}}$ manoeuvres were used in this study to measure temporal differences in diffusing capacity using a rapid response carbon monoxide analyzer.

OBJECTIVE: To determine whether abnormalities in the lung periphery can be detected in smokers with normal forced expired volumes in $1 \mathrm{~s}$ using the three-equation diffusing capacity $\left(\mathrm{DLco}^{\mathrm{SB}}-3 \mathrm{EQ}\right)$ among small alveolar gas samples and whether the abnormalities correlate with increases in peripheral ventilation inhomogeneity.

PARTICIPANTS AND DESIGN: Cross-sectional study in 21 smokers and 21 nonsmokers all with normal forced exhaled flow rates.

METHODS: Both smokers and nonsmokers performed $\mathrm{SBW}_{\mathrm{SM}}$ manoeuvres consisting of slow inhalation of test gas from functional residual capacity to one-half inspiratory capacity with either 0 or $10 \mathrm{~s}$ of breath holding and slow exhalation to residual volume (RV). They also performed conventional vital capacity single breath $\left(\mathrm{SBW}_{\mathrm{VC}}\right)$ manoeuvres consisting of slow inhalation of test gas from
$\mathrm{RV}$ to total lung capacity and, without breath holding, slow exhalation to RV. DLco ${ }^{\mathrm{SB}}-3 \mathrm{EQ}$ was calculated from the total alveolar gas sample. DLco ${ }^{\mathrm{SB}}-3 \mathrm{EQ}$ was also calculated from four equal sequential, simulated aliquots of the total alveolar gas sample. DLco ${ }^{\mathrm{SB}}-3 \mathrm{EQ}$ values from the four alveolar samples were normalized by expressing each as a percentge of $\mathrm{DLco}^{\mathrm{SB}}-3 \mathrm{EQ}$ from the entire alveolar gas sample. An index of variation $\left(\mathrm{D}_{\mathrm{I}}\right)$ among the small-sample $\mathrm{DLco}^{\mathrm{SB}}{ }_{-3 \mathrm{EQ}}$ values was correlated with the normalized phase III helium slope $\left(S_{n}\right)$ and the mixing efficiency $\left(E_{\text {mix }}\right)$. RESULTS: For SBW $\mathrm{SM}_{\mathrm{SM}}, \mathrm{D}_{\mathrm{I}}$ was increased in smokers at $0 \mathrm{~s}$ of breath holding compared with nonsmokers, and correlated with age, smoking pack-years and $S_{\mathrm{n}}$. The decrease in $\mathrm{D}_{\mathrm{I}}$ with breath holding was greater in smokers and correlated with the change in $\mathrm{S}_{\mathrm{n}}$ with breath holding. For $\mathrm{SBW}_{\mathrm{vC}}$ manoeuvres, there were no differences due to smoking in $S_{n}$ or $\mathrm{E}_{\mathrm{mix}}$, but $\mathrm{D}_{\mathrm{I}}$ was increased in smokers and correlated with age and smoking pack-years, but not with $S_{n}$.

CONCLUSIONS: For $\mathrm{SBW}_{\mathrm{SM}}$ manoeuvres the increase in $\mathrm{D}_{\mathrm{I}}$ in smokers correlated with breath hold time-dependent increases in $S_{n}$, suggesting that the changes in $D_{\text {I }}$ reflected the same structural alterations that caused increases in peripheral ventilation inhomogeneity. For $\mathrm{SBW}_{\mathrm{VC}}$ manoeuvres, the increase in $D_{I}$ in smokers was not associated with changes in ventilation inhomogeneity, suggesting that the effect of smoking on $\mathrm{D}_{\mathrm{I}}$ during this manoeuvre was due to smoke-related changes in alveolar capillary diffusion, rather than due solely to alterations in the distribution of ventilation.

Key Words: Diffusion index, Inhomogeneity, Slope of phase III, Small airways, Three-equation diffusing capacity, Tobacco smoking

Correspondence: Dr DJ Cotton, Division of Respiratory Medicine, Department of Medicine, Royal University Hospital, Room 37, Ellis Hall, Saskatoon, Saskatchewan S7N OW8. Telephone 306-966-7947, fax 306-966-8021, e-mail cottond@ sdh.sk.ca 


\section{L'hétérogénéité de la capacité de diffusion dans des petits échantillons de gaz alvéolaire augmente chez les fumeurs}

\begin{abstract}
HISTORIQUE : Bien que l'emphysème centrolobulaire et l'inflammation des petites voies aériennes, l'inflammation de l'interstitium et des alvéoles, puissent être décelés à l'aide d'un examen pathologique dans les poumons des fumeurs présentant par ailleurs une fonction pulmonaire relativement bien conservée, ces changements sont difficiles à évaluer au moyen des tests physiologiques disponibles. Parce que le test de rinçage en respiration unique sous-maximale $\left(\mathrm{SBW}_{\mathrm{SM}}\right)$ permet de mieux déceler les anomalies dans l'hétérogénéité de la ventilation dans la périphérie du poumon chez les fumeurs comparativement à l'épreuve classique se basant sur la capacité vitale, le test de $\mathrm{SBW}_{\mathrm{SM}}$ a été utilisé dans la présente étude pour mesurer les différences temporelles dans la capacité de diffusion à l'aide d'un analyseur rapide de monoxyde de carbone.

OBJECTIF : Déterminer si les anomalies de la ventilation dans la périphérie du poumon peuvent être décelées chez les fumeurs dont le volume expiratoire maximum/seconde (VEMS) est normal au moyen de la méthode de la capacité de diffusion à trois équations ( $\left.\mathrm{DL}_{\mathrm{co}} \mathrm{SB}_{-3 \mathrm{EQ}}\right)$ dans des petits échantillons de gaz alvéolaire, et si les anomalies corrèlent avec les augmentations de l'hétérogénéité de la ventilation périphérique.
\end{abstract}

PARTICIPANTS ET MODÈLE : Étude transversale auprès de 21 fumeurs et de 21 non-fumeurs présentant tous des débits expiratoires normaux.

MÉTHODES : Les fumeurs et les non-fumeurs ont été soumis au test de $\mathrm{SBW}_{\mathrm{SM}}$ consistant en une inhalation lente du gaz test à partir de la capacité résiduelle fonctionnelle jusqu'à la première moitié de la capacité inspiratoire, et après $0 \mathrm{~s}$ ou $10 \mathrm{~s}$ en apnée, en expirant lentement jusqu'au volume résiduel (VR). Ils ont aussi été soumis au test classique de rinçage basé sur la capacité vitale $\left(\mathrm{SBW}_{\mathrm{VC}}\right)$ consistant en une inhalation lente du gaz test à partir du VR jusqu'à la capacité pulmonaire totale et, sans apnée, en expirant lentement jusqu'au VR. La $\mathrm{DL}_{\mathrm{co}} \mathrm{SB}_{-} 3 \mathrm{EQ}$ a été calculée à partir de l'échantillon complet de gaz alvéolaire. $\mathrm{La} \mathrm{DL}_{\mathrm{co}} \mathrm{SB}_{-} 3 \mathrm{EQ}$ a aussi été calculée à partir de quatre parties aliquotes égales, simulées et en séquence de la totalité de l'échantillon de gaz alvéolaire. Les valeurs de la $\mathrm{DL}_{\mathrm{co}} \mathrm{SB}_{-} 3 \mathrm{EQ}$ provenant des quatre échantillons alvéolaires ont été standardisées en exprimant chacune d'entre elles comme un pourcentage de $\mathrm{la}_{\mathrm{DL}} \mathrm{co}_{-} \mathrm{SB}_{-} \mathrm{EQ}$ obtenue à partir de la totalité de l'échantillon de gaz alvéolaire. Un index de variation $\left(\mathrm{D}_{\mathrm{I}}\right)$ parmi les valeurs de la $\mathrm{DL}_{\mathrm{co}} \mathrm{SB}_{-} 3 \mathrm{EQ}$ provenant des petits échantillons a été corrélé avec la pente de la phase III normalisée de l'hélium $\left(\mathrm{S}_{\mathrm{n}}\right)$ et l'efficacité de la mixique $\left(\mathrm{E}_{\mathrm{mix}}\right)$.

RÉSULTATS : Dans le cas du $\mathrm{SBW}_{\mathrm{SM}}$, le $\mathrm{D}_{\mathrm{I}}$ augmentait chez les fumeurs à $0 \mathrm{~s}$ d'apnée comparativement aux non-fumeurs, et corrélait avec l'âge, le nombre de paquets/année et la $\mathrm{S}_{\mathrm{n}}$. La diminution de $\mathrm{D}_{\mathrm{I}}$ en apnée était plus importante chez les fumeurs et corrélait avec le changement dans la $S_{n}$ en apnée. Pour ce qui est des épreuves du $\mathrm{SBW}_{\mathrm{VC}}$, il n'y avait aucune différence attribuable au fait de fumer dans la $\mathrm{S}_{\mathrm{n}}$ ou dans le $\mathrm{E}_{\mathrm{mix}}$, cependant, le $\mathrm{D}_{\mathrm{I}}$ augmentait chez les fumeurs et corrélait avec l'âge et le nombre de paquets/année, mais pas avec la $S_{n}$.

CONCLUSIONS : En ce qui concerne les épreuves de $\mathrm{SBW}_{\mathrm{SM}}$, l'augmentation de $\mathrm{D}_{\mathrm{I}}$ chez les fumeurs corrélait avec les augmentations de la $\mathrm{S}_{\mathrm{n}}$ dépendante du temps d'apnée ce qui laisse croire que les changements dans $\mathrm{D}_{\mathrm{I}}$ reflétaient les mêmes altérations structurales qui causaient une augmentation de l'hétérogénéité de la ventilation périphérique. Dans le cas des épreuves de $\mathrm{SBW}_{\mathrm{VC}}$, l'augmentation de $D_{\text {I }}$ chez les fumeurs n'était pas associée avec les changements dans l'hétérogénéité de la ventilation, ce qui permet de croire que l'effet de fumer sur $\mathrm{D}_{\mathrm{I}}$ pendant cette épreuve était dû aux changements induits par la fumée sur la diffusion capillaire alvéolaire plutôt qu'aux seules altérations de la distribution de la ventilation.
$\mathrm{S}$

moking is associated with inflammation and fibrosis in small airways and alveoli (1-3), and vascular deficiency emphysema $(4,5)$. Using conventional vital capacity single breath washout (SBWVC) manoeuvres without breath holding, abnormalities in the phase III slope of nitrogen were found in healthy smokers which correlated with pathological changes in the small airways (3). However, prospective studies showed that the abnormalities in SBWVC maneouvres did not specifically identify those at risk of developing chronic airflow limitation (6). Others have proposed the use of more complex physiological techniques that highlight abnormalities in ventilation inhomogeneity in the lung periphery (7) using multibreath washout techniques (8) and gases of differing diffusivities (9), but these approaches are more demanding to implement as screening tests in large populations.

A refinement of $\mathrm{SBW}_{\mathrm{VC}}$ manoeuvres with potential application to epidemiological investigation was proposed because it might provide more information about peripheral ventilation inhomogeneity $(10,11)$. This refinement $\left(\mathrm{SBW}_{\mathrm{SM}}\right)$ consisted of reducing the inspired volume of the SBW manoeuvre to one-half inspiratory capacity (IC) and initiating the SBW manoeuvre at a preinspiratory lung volume of functional residual capacity (FRC). In smokers with normal forced exhaled flow rates, abnormalities in the normalized phase III slope for helium $\left(\mathrm{S}_{\mathrm{n}}\right)$ were detected using $\mathrm{SBW}_{\mathrm{SM}}$ that were not evident using $\mathrm{SBW}_{\mathrm{VC}}$ manoeuvres (11).

The difference between the two types of manoeuvres was thought to be caused by differences in the relative contributions of several types of ventilation inhomogeneity. For
$\mathrm{SBW}_{\mathrm{VC}}$ manoeuvres, a dominant mechanism of nonuniform gas distribution was convective dependent, topographical ventilation inhomogeneity due to asynchronous emptying of large regions with unequal specific ventilations (12-14). In contrast with $\mathrm{SBW}_{\mathrm{SM}}$ manoeuvre, the major origin of the ventilation inhomogeneity was in the lung periphery due to either intraregional convective dependent gradients among closely adjacent regions or the interaction of diffusion and convection at peripheral branch points within the acinus $(12,15)$. A characteristic feature of inhomogeneity due to the interaction of convection and diffusion at peripheral branch points, and to a lesser extent to inhomogeneity due to intraregional convective dependent gradients, was that the tracer gas concentration gradients caused by this type of inhomogeneity were markedly diminished with short periods of breath holding. This is as a result of cardiogenic and diffusive gas mixing within the lung periphery $(7,12)$. Hence, the steeper $\mathrm{S}_{\mathrm{n}}$ in smokers for $\mathrm{SBW}_{\mathrm{SM}}$ manoeuvres at $0 \mathrm{~s}$ of breath holding and the greater change in $S_{n}$ in smokers over short periods of breath holding indicated a superior ability of the $\mathrm{SBW}_{\mathrm{SM}}$ manoeuvre to identify an abnormality in peripheral ventilation inhomogeneity in smokers compared with the $\mathrm{SBW}_{\mathrm{VC}}$ manoeuvre (11).

In this study, we extended the analysis of $\mathrm{SBW}_{\mathrm{SM}}$ manoeuvre in smokers by evaluating the simultaneously measured disappearance curve of carbon monoxide. The three-equation diffusing capacity for carbon monoxide $\left(\mathrm{DLCO}^{\mathrm{SB}}-3 \mathrm{EQ}\right)$, measured from four equal and sequential aliquots of the total alveolar gas sample, was also affected by 
manoeuvres that altered the distribution of ventilation in the lung periphery in normal nonsmoking subjects (16). Compared with the predicted carbon monoxide washout for a uniform lung model, the carbon monoxide concentration was higher than expected early in exhalation and lower than expected later in exhalation in normal subjects for $\mathrm{SBW}_{\mathrm{SM}}$ manouvre without breath holding. This resulted in a reduced $\mathrm{DLCO}^{\mathrm{SB}}-3 \mathrm{EQ}$ when calculated from the first alveolar sample early in exhalation but an increased DLCO ${ }^{\mathrm{SB}}$-3EQ when measured from the fourth sample at near residual volume $(\mathrm{RV})$ in normal subjects. These differences in $\mathrm{DLCO}^{\mathrm{SB}}-3 \mathrm{EQ}$ among small alveolar gas samples were attributed to timedependent carbon monoxide concentration gradients in the lung periphery because the effect largely disappeared with short periods of breath holding (16).

We wished to determine whether the changes in $\mathrm{DLCO}^{\mathrm{SB}}$-3EQ among small alveolar gas samples were abnormal in smokers with otherwise relatively normal lung function. We hypothesized that smoking would magnify the degree of nonuniformity $\left(\mathrm{D}_{\mathrm{I}}\right)$ of $\mathrm{DLCO}{ }^{\mathrm{SB}}-3 \mathrm{EQ}$ measured from small alveolar gas samples at $0 \mathrm{~s}$ of breath holding in smokers, particularly for $\mathrm{SBW}_{\mathrm{SM}}$ manoeuvres. As well we thought that $\mathrm{D}_{\mathrm{I}}$ would correlate with increases in peripheral ventilation inhomogeneity in smokers using the normalized phase III helium slope (11), but would disappear with short periods of breath holding (16).

\section{PATIENTS AND METHODS}

Study group: Twenty-one smokers and 21 nonsmokers were recruited from the community and hospital personnel. In both groups as previously reported (11), subjects denied recent respiratory symptoms. Spirometric testing revealed that the forced vital capacity (FVC), the forced expired volume in $1 \mathrm{~s}$ $\left(\mathrm{FEV}_{1}\right)$ and the maximal mid-expiratory flows $\left(\mathrm{FEF}_{25-75}\right)$ were within the $95 \%$ confidence limits of normal using previously reported regressions (17). Smokers had a current cigarette consumption of at least 10 cigarettes per day and a cumulative exposure of at least four pack-years. Nonsmokers had no current exposure and had smoked less than 100 cigarettes in their lifetime.

Apparatus and equipment: Using equipment previously described $(11,18)$, seated subjects, at rest, breathed test gas containing $0.3 \%$ carbon monoxide, $10 \%$ helium, $21 \%$ oxygen and the balance nitrogen through a low dead space twoway valve. Flow and volume were measured continuously with a pneumotach mounted in the wall of a bag-in-box system, helium concentration with a mass spectrometer and carbon monoxide concentration with a rapidly responding infrared analyzer. Throughout each SBW, including two to three preceding tidal breaths and a standardized deep breath, flow, volume, carbon monoxide and helium signals were stored digitally $(50 \mathrm{~Hz})$ for later computer analysis.

Protocol: The protocol used in this study has been previously reported (11). All SBWs were preceded by a standardized deep breath of room air (19) and were performed singly in random order on one study day. An individualized volume versus time 'template' of the prescribed manoeuvre (18) was

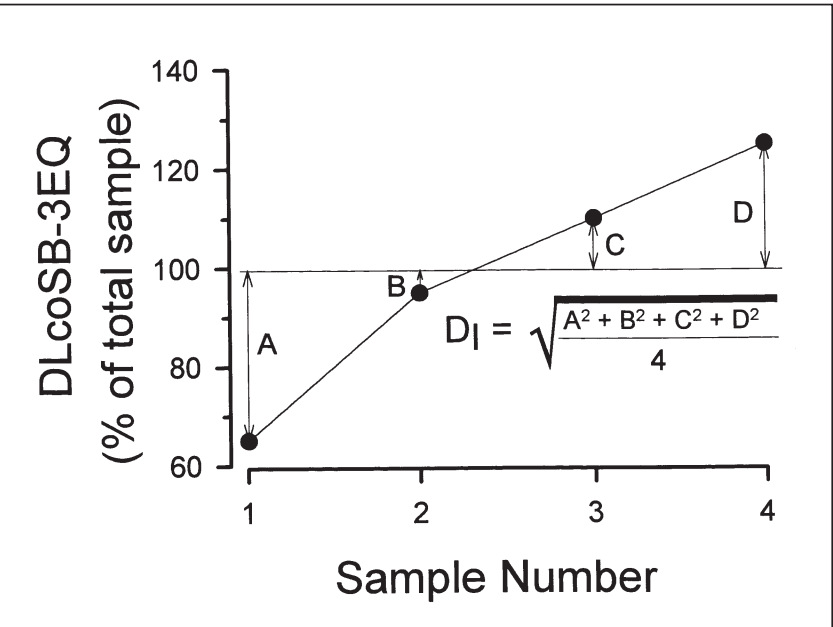

Figure 1) Three-equation diffusing capacity for carbon monoxide $\left(D L C O{ }^{S B}-3 E Q\right)$ values measured from the four equal alveolar gas samples are normalized by expressing them as a percentage of $D L C O{ }^{S B}-3 E Q$ measured from the total alveolar gas sample (y axis). Values (sample 1 to 4) are shown for a representative submaximal single breath washout manoeuvre at $O \mathrm{~s}$ of breath holding. $D L C O^{S B}-3 E Q$ value for sample 1, measured at high expired lung volumes, is below $100 \%$ whereas subsequent $D L C O{ }^{S B}-3 E Q$ values rise progressively above $100 \%$. For each of the four normalized $D L C O^{S B}-3 E Q$ values measured from the four equal alveloar gas samples, the difference between each of the small samples and the normalized $D L C O^{S B}-3 E Q$ from the total aveloar gas sample was calculated ( $A, B, C, D)$. The root mean square difference of the four samples, the degree of diffusion nonuniformity $\left(D_{I}\right)$ is calculated using $A, B, C$ and $D$ as shown in the insert. $D_{I}$ is $27 \%$ in this example.

displayed on a monitor to assist subjects in performing the following SBWs: SBW $\mathrm{SM}$ manoeuvres consisting of slow inhalation from FRC to one-half IC, with either $0 \mathrm{~s}$ or $10 \mathrm{~s}$ of breath holding and slow exhalation to RV; and conventional $\mathrm{SBW}_{\mathrm{VC}}$ manoeuvres consisting of slow inhalation from RV to total lung capacity, and without breath holding, slow exhalation to RV. All inspired and expired flows for the preceding deep breath and for all SBW manoeuvres were maintained at $0.5 \mathrm{~L} / \mathrm{s}$.

Analysis: For each SBW, the inspired and expired volumes, inspiratory and expiratory times, and the breath hold time were measured (11). RV was calculated by measuring the mass of helium inhaled and exhaled to determine the mass of helium remaining in the lung, as previously described $(18,20,21)$. It was assumed that the mean helium concentration in the lung at RV was equal to the measured helium concentration at end expiration.

Because SBW manoeuvres were analyzed after storage of the flow, carbon monoxide and helium signals in digital form, DLco ${ }^{\mathrm{SB}}$-3EQ from any one or a number of simulated alveolar samples from the same manoeuvre could be analyzed (18). In this analysis the three-equation diffusing capacity using the simulated entire alveolar gas sample was computed $(13,18,20)$. DLCO ${ }^{\mathrm{SB}}$-3EQ from the mean carbon monoxide concentration in each of four simulated sequential and equal alveolar gas samples (16) was calculated, and each $\mathrm{DLCO}^{\mathrm{SB}}$-3EQ value was normalized by expressing it as a percentage of $\mathrm{DLCO}^{\mathrm{SB}}-3 \mathrm{EQ}$ calculated from the entire alveolar 
TABLE 1

Group mean values ( \pm SD) of single breath washout manoeuvres for nonsmokers and smokers during conventional vital capacity manoeuvres without breath holding (SBWvc) and submaximal (SBW $\mathrm{Sm}$ ) manoeuvres at 0 and $10 \mathrm{~s}$ of breath holding

\begin{tabular}{|c|c|c|c|c|c|c|}
\hline \multirow[b]{3}{*}{ Breath hold time } & \multicolumn{2}{|c|}{ SBWvc } & \multicolumn{4}{|c|}{ SBW } \\
\hline & Nonsmoker & Smoker & Nonsmoker & Smoker & Nonsmoker & Smoker \\
\hline & \multicolumn{2}{|c|}{$0 \mathrm{~s}$} & \multicolumn{2}{|c|}{$0 \mathrm{~s}$} & \multicolumn{2}{|c|}{$10 \mathrm{~s}$} \\
\hline Expired volume (L) & $4.46 \pm 0.95$ & $4.34 \pm 1.1$ & $2.99 \pm 0.71$ & $3.00 \pm 0.98$ & $2.96 \pm 0.77$ & $2.97 \pm 0.98$ \\
\hline $\begin{array}{l}\text { Absolute maximum } \\
\text { end-inspired volume (L) }\end{array}$ & $6.13 \pm 1.27$ & $6.18 \pm 1.60$ & $4.74 \pm 1.09$ & $4.92 \pm 1.42$ & $4.79 \pm 1.15$ & $4.99 \pm 1.40$ \\
\hline $\begin{array}{l}\text { Absolute end-inspired } \\
\text { volume (L) }\end{array}$ & $1.67 \pm 0.42$ & $1.83 \pm 0.50$ & $3.14 \pm 0.93$ & $3.38 \pm 1.17$ & $3.14 \pm 0.97$ & $3.41 \pm 1.15$ \\
\hline $\mathrm{DLco}^{\mathrm{SB}}-3 \mathrm{EQ}$ & $33.5 \pm 7.6$ & $29.0 \pm 6.4^{*}$ & $34.3 \pm 8.2$ & $28.9 \pm 7.8^{*}$ & $33.5 \pm 8.0$ & $29.9 \pm 6.8$ \\
\hline$D_{\text {I }}(\%)$ & $5.1 \pm 2.7$ & $7.6 \pm 4.3^{*}$ & $17.8 \pm 6.7$ & $42.4 \pm 29.9^{\star \star \star}$ & $3.4 \pm 1.1$ & $5.0 \pm 2.8^{*}$ \\
\hline$\Delta \mathrm{D}_{\mathrm{l}}(\%)$ & & & $14 \pm 6$ & $37 \pm 28^{\star \star \star}$ & & \\
\hline $\mathrm{S}_{\mathrm{n}}\left(\mathrm{mL}^{-1}\right)$ & $-14.4 \pm 7.9$ & $-16.1 \pm 8.3$ & $-64.9 \pm 29.5$ & $-134.5 \pm 5.3^{\star \star \star}$ & $-27.7 \pm 15.4$ & $-59.2 \pm 43.5^{\star *}$ \\
\hline Mixing efficiency (\%) & $96.8 \pm 1.3$ & $96.0 \pm 1.6$ & $89.9 \pm 2.6$ & $87.9 \pm 4.2$ & $93.1 \pm 1.7$ & $91.6 \pm 3.2$ \\
\hline
\end{tabular}

Significance of comparisons between smokers and nonsmokers.: ${ }^{*} P<0.05,{ }^{* *} P<0.01,{ }^{* * *} P<0.001 . D L C O^{S B}-3 E Q$ Three equation diffusing capacity for carbon monoxide; $D_{l}$ Degree of uniformity, root mean square difference of $D L C O{ }^{S B}$-3EQ calculated from the four equal alveolar gas samples that are normalized by expressing them as a percentage of $D L C O^{S B}-3 E Q$ measured from the total alveolar gas sample; $S_{n}$ Normalized phase III slope for the tracer gas helium

gas sample (18). For all DLco ${ }^{\mathrm{SB}}-3 \mathrm{EQ}$ calculations, the mean carbon monoxide concentration in the exhaled alveolar gas of the deep breath of room air immediately preceding the single breath manoeuvre was used as the estimate of the carbon monoxide back pressure for the subsequent SBW manoeuvre (22).

$\mathrm{D}_{\mathrm{I}}$ described the degree to which the four DLco ${ }^{\mathrm{SB}}-3 \mathrm{EQ}$ values measured from the four alveolar gas samples deviated from the single $\mathrm{DLco}^{\mathrm{SB}}-3 \mathrm{EQ}$ value measured from the entire alveolar gas sample by calculating the root-mean-square difference (18) of the normalized DLco ${ }^{\mathrm{SB}}-3 \mathrm{EQ}$ values (Figure 1). $D_{I}$ quantified the degree of nonuniformity of $\mathrm{DLco}^{\mathrm{SB}}$-3EQ measured from the four small samples, each normalized by DLco ${ }^{\mathrm{SB}}$-3EQ measured from the total sample.

As previously reported (11) the phase III helium slope $(\Delta \mathrm{He} / \mathrm{L})$ between $33 \%$ and $67 \%$ of the exhaled volume was measured, and the phase III slope $\left(\mathrm{S}_{\mathrm{n}}\right)$ was normalized by dividing $\Delta \mathrm{He} / \mathrm{L}$ by the predicted ideal, mean end-inspired alveolar helium concentration $\left([\mathrm{He}]_{\mathrm{A}}\right.$ PRED $)(13,18)$. The mixing efficiency $\left(\mathrm{E}_{\text {mix }}\right)$ was calculated using a previously described computer algorithm (18).

Statistics: Group mean data for smokers and nonsmokers were compared using unpaired Student's $t$ tests. Differences due to the SBW manoeuvre and to breath hold time were assessed using paired Student's $t$ tests in both smokers and nonsmokers. Correlations were performed using linear regression analysis.

\section{RESULTS}

The characteristics of the smoking and nonsmoking groups, which have been previously reported (11), were similar in terms of sex distribution (smokers: 12 women and nine men; nonsmokers: 10 women and 11 men), age (smokers $39 \pm 8$ years; nonsmokers $38 \pm 7$ years, mean $\pm \mathrm{SD}$ ) and height (smokers $172 \pm 10 \mathrm{~cm}$; nonsmokers $174 \pm 10 \mathrm{~cm}$ ). There were no significant differences in FVC (smokers $105 \pm 10 \%$ predicted; nonsmokers $101 \pm 8 \%$ predicted) or $\mathrm{FEV}_{1}$ (smokers $100 \pm 9 \%$ predicted; nonsmokers $102 \pm 8 \%$ predicted). The $\mathrm{FEF}_{25-75}$ was smaller $(\mathrm{P}<0.05)$ in smokers $(90 \pm 24 \%$ predicted) than in nonsmokers (106 $\pm 21 \%$ predicted). The smokers had a mean of $21 \pm 12$ pack-years of cigarette smoking (range of four to 55 pack-years). There were no differences in the expired volume, maximum end-inspired volume, pre-inspiratory lung volume or breath hold time for comparable manoeuvres between smokers and nonsmokers (Table 1).

SBW $_{\text {SM }}$ at $0 \mathrm{~s}$ of breath holding: $\mathrm{DLCO}^{\mathrm{SB}}-3 \mathrm{EQ}$ from the total alveolar sample was slightly reduced in smokers (Table 1; $\mathrm{P}<0.05)$. DLCO ${ }^{\mathrm{SB}}$-3EQ measured from small alveolar gas samples was reduced in the first alveolar sample, measured at high lung volumes just after alveolar dead space clearance, but increased progressively in subsequent samples (Figure 2, left graph). $D_{I}$ was therefore greater in smokers $(42 \pm 29 \%)$ than in nonsmokers $(18 \pm 7 \%)$ (Table $1 ; \mathrm{P}<0.001)$. $\mathrm{D}_{\text {I }}$ correlated with age in smokers (Figure $3 ; \mathrm{r}^{2}=0.23 ; \mathrm{P}=0.026$ ) and pack-years of smoking (Figure $\left.3 ; \mathrm{r}^{2}=0.36 ; \mathrm{P}=0.004\right)$ ). $\mathrm{S}_{\mathrm{n}}$, but not $E_{\text {mix }}$, was also markedly increased in smokers (Table 1 ; $\mathrm{P}<0.001)$. $\mathrm{D}_{\mathrm{I}}$ at $0 \mathrm{~s}$ of breath holding correlated significantly with $S_{n}$ at $0 \mathrm{~s}$ of breath holding in both smokers $\left(\mathrm{r}^{2}=0.63\right.$; $\mathrm{P}<0.001)$ and nonsmokers $\left(\mathrm{r}^{2}=0.38 ; \mathrm{P}<0.01\right)$ (Figure 4). The day-to-day coefficient of variation of $\mathrm{D}_{\mathrm{I}}$ for this manoeuvre was $8.0 \pm 4.6 \%$ in 10 normal subjects whose value were repeated on five successive days (22).

Effect of $10 \mathrm{~s}$ of breath holding on $\mathrm{SBW}_{\mathrm{SM}}$ : $\mathrm{DLCO}^{\mathrm{SB}}-3 \mathrm{EQ}$ from the total alveolar gas sample was similar between smokers and nonsmokers (Table 1). For DLco ${ }^{\mathrm{SB}}$-3EQ measured from small alveolar gas samples there was markedly less deviation of all four samples from DLco ${ }^{\mathrm{SB}}-3 \mathrm{EQ}$ measured from the total sample (Figure 2). However, the pattern of change remained similar to that observed at $0 \mathrm{~s}$ of breath 


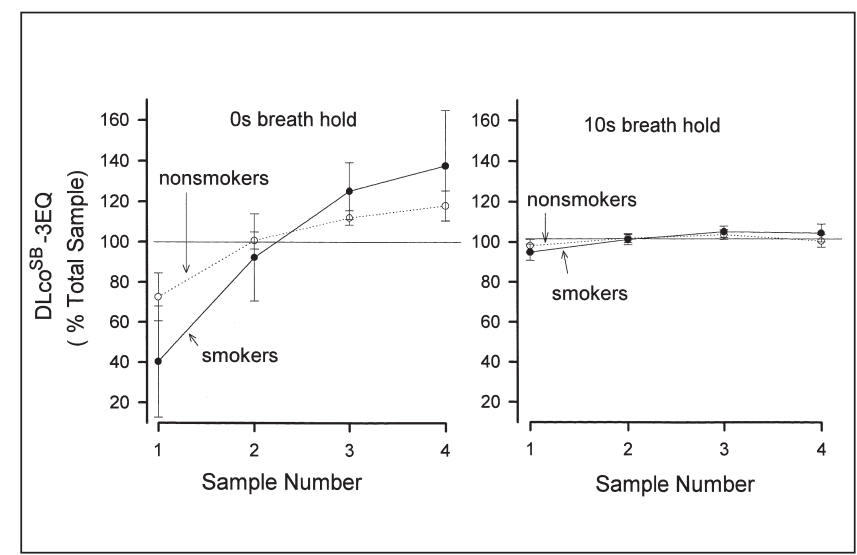

Figure 2) Group mean values for the four normalized three-equation diffusing capacity for carbon monoxide $\left(D L C O^{S B}-3 E Q\right)$ values (error bars, $\pm S D$ ) for nonsmokers $(\mathrm{O})$ and smokers ()$\left.^{\prime}\right)$ at $0 \mathrm{~s}$ of breath holding (left diagram) and after $10 \mathrm{~s}$ of breath holding (right diagram). Because the $D L C O{ }^{S B}-3 E Q$ values deviate more from $D L C O{ }^{S B}-3 E Q$ measured from the whole sample in smokers, degree of nonuniformity $\left(D_{I}\right)$ is larger in this group $(42 \pm 29 \%$, mean $\pm S D)$ than in nonsmokers $(18 \pm 6 \%)$ at $0 \mathrm{~s}$ of breath holding. At $10 \mathrm{~s}$ of breath holding the four samples are almost identical to $D L C O{ }^{S B}-3 E Q$ from the total alveolar gas sample. The degree of uniformity dramatically decreases with breath holding in both groups, but remains significantly higher in smokers

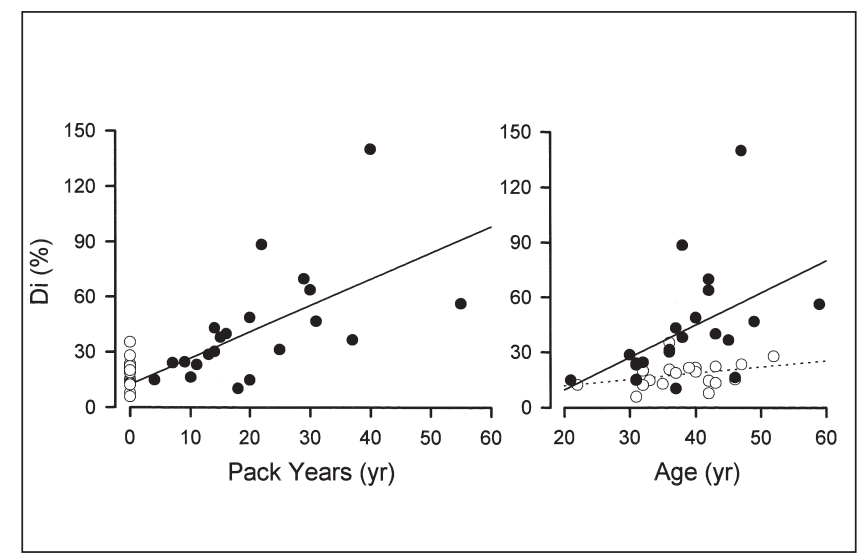

Figure 3) For submaximal single breath washout manoeuvres degree of diffusion nonuniformity $\left(D_{I}\right)$ correlates with pack-years of smoking (left diagram) in smokers $\left(r^{2}=0.36 ; P=0.004\right)$ and with age in smokers $\left(r^{2}=0.23 ; P=0.026\right)$, but not in nonsmokers (right diagram, $\left.r^{2}=0.12\right)$. $\bigcirc$ with dashed line Nonsmokers; 1 with solid line Smokers

holding with DLco ${ }^{\mathrm{SB}}-3 \mathrm{EQ}$ being lower for sample 1 but higher for sample 4 . Whereas $\mathrm{D}_{\mathrm{I}}$ was markedly reduced, compared with those measured at $0 \mathrm{~s}$ of breath holding, it remained slightly, but significantly higher in smokers $(5 \pm 3 \%)$ than nonsmokers $(3 \pm 1 \%)$ (Table 1$)$ and correlated with pack-years of smoking $\left(\mathrm{r}^{2}=0.51 ; \mathrm{P}<0.001\right)$ and with $\mathrm{S}_{\mathrm{n}}$ $\left(r^{2}=0.22 ; \mathrm{P}<0.05\right)$.

Change in $\mathrm{D}_{\mathrm{I}}$ with breath holding for SBW $\mathrm{SM}$ : The decrease in $\mathrm{D}_{\mathrm{I}}$ from $0 \mathrm{~s}$ to $10 \mathrm{~s}$ of breath holding correlated with $\mathrm{S}_{\mathrm{n}}$ measured at $0 \mathrm{~s}$ of breath holding in both nonsmokers $\left(r^{2}=0.37 ; \mathrm{P}<0.01\right)$ and smokers $\left(\mathrm{r}^{2}=0.61 ; \mathrm{P}<0.01\right)$, but did not correlate with $S_{n}$ at $10 s$ of breath holding in either group. In smokers the decrease in $\mathrm{D}_{\mathrm{I}}$ with breath holding time $\left(\Delta \mathrm{D}_{\mathrm{I}}\right)$

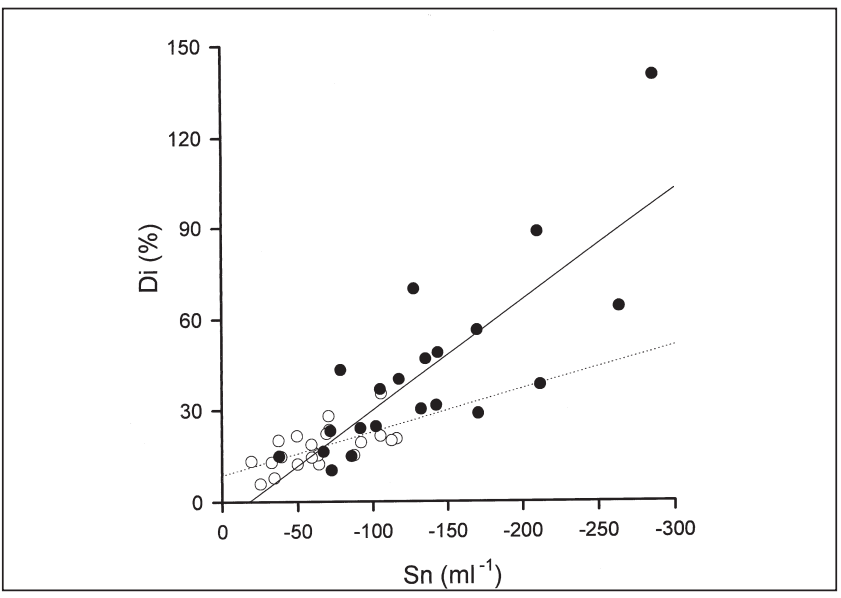

Figure 4) Degree of diffusion nonuniformity $\left(D_{I}\right)(\%)$ correlates with the normalized phase III helium slope $\left(S_{\mathrm{n}}\right)$ for submaximal single breath washout $\left(S B W_{S M}\right)$ manoeuvres at 0 s of breath holding in both smokers $\left(r^{2}=0.63, P<0.001\right.$, solid line) and in nonsmokers $(r=0.38, P<0.01$, dashed line). For the nonsmokers and smokers combined, $\left(r^{2}=0.69, P<0.001\right)$. $\bigcirc$ Nonsmokers; Smokers

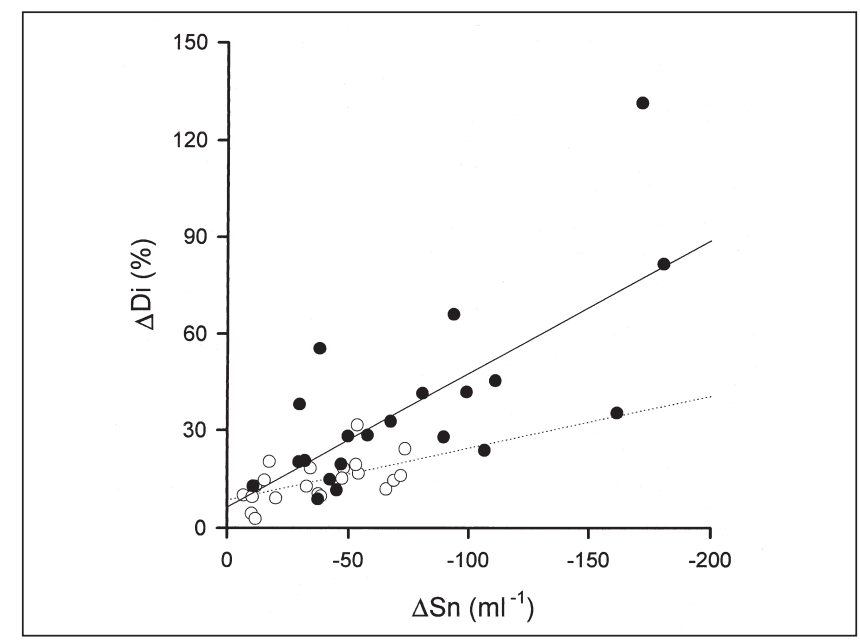

Figure 5) The reduction in degree of diffusion nonuniformity $\left(D_{I}\right)$ from $0 \mathrm{~s}$ to $10 \mathrm{~s}$ of breath holding $\left(\Delta D_{I}\right)$ for submaximal single breath washout $\left(S B W_{S M}\right)$ (y axis) correlates with the change in normalized phase III helium slope $\left(S_{n}\right)$ from 0 to 10 s of breath holding $\left(\Delta S_{n}\right)$ for $S B W_{\mathrm{SM}}$ manoeuvres in both smokers $\left(r^{2}=0.51, P<0.001\right.$, solid line) and nonsmokers $\left(r^{2}=0.31, P<0.01\right.$, dashed line $) . \bigcirc$ Nonsmokers; Smokers

was significantly greater in smokers than nonsmokers (Table 1) and correlated with the corresponding change in $S_{n}$ $\left(\Delta S_{n}\right)$ (Figure $\left.5, r^{2}=0.51 ; P<0.001\right)$. In nonsmokers $\Delta D_{\text {I }}$ and $\Delta S_{n}$ were both less than in smokers, but the correlation between them was also significant $\left(\mathrm{r}^{2}=0.31 ; \mathrm{P}<0.01\right)$.

SBW $_{\text {VC: }}$ DLCO ${ }^{\mathrm{SB}}$-3EQ measured from the whole sample was slightly lower in smokers (Table 1 ). $\mathrm{D}_{\text {I }}$ was significantly increased in smokers (Table $1 ; \mathrm{P}<0.05)$ and correlated with age in smokers $\left(\mathrm{r}^{2}=0.48 ; \mathrm{P}<0.001\right)$ but not in nonsmokers, and with pack-years of smoking $\left(\mathrm{r}^{2}=0.55 ; \mathrm{P}<.001\right)$ (Figure $6)$. However, there were no differences between smokers and nonsmokers for either $S_{n}$ or $E_{\text {mix }}$ (Table 1) as previously reported (11). Furthermore, $D_{I}$ did not correlate with $S_{n}$ in either 


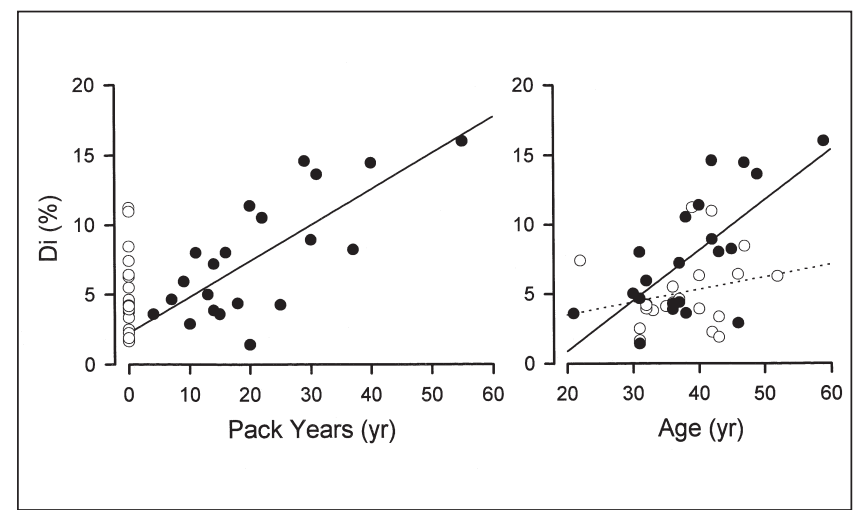

Figure 6) For vital capacity single breath washout manoeuvres degree of diffusion nonuniformity $\left(D_{I}\right)$ correlates with pack-years of smoking (left diagram) in smokers $\left(\mathrm{r}^{2}=0.55, P<0.001\right)$ and with age in smokers $\left(r^{2}=0.48, P<0.01\right)$ but not in nonsmokers (right diagram). O Nonsmokers; O Smokers; yr Years

smokers or nonsmokers. The day-to-day coefficient of variation of $\mathrm{D}_{\mathrm{I}}$ for this manoeuvre was $1.6 \pm 5.9 \%$ in 10 normal subjects who repeated the manoeuvre on five successive days (22).

\section{DISCUSSION}

The most remarkable finding in this study was that $D_{I}$ was significantly higher in smokers for $\mathrm{SBW}_{\mathrm{SM}}$ at $0 \mathrm{~s}$ of breath holding and correlated with cumulative pack-years of smoking. The fact that, for these manoeuvres, $D_{I}$ correlated with both age and pack-years of smoking in smokers, but was not affected by age in nonsmokers (Figure 3), implied a specific effect of smoking on $\mathrm{D}_{\mathrm{I}}$ that could not be explained by ageing. Although the precise pathological changes responsible for the increase in $\mathrm{D}_{\mathrm{I}}$ in smokers for $\mathrm{SBW}_{\mathrm{SM}}$ manoeuvres at $0 \mathrm{~s}$ of breath holding must await future structure-function correlations, the effects of breath holding on both $\mathrm{D}_{\mathrm{I}}$ and simultaneous measurements of ventilation inhomogeneity allow us to draw some inferences about the possible mechanisms for the effects of smoking on $\mathrm{D}_{\mathrm{I}}$.

Smoking produces a number of pathological lesions in the lung $(1-3,23,24)$. Recent observations using computed tomography (CT) revealed surprisingly common abnormalities in smokers with relatively normal lung function. The abnormalities consisted of ground glass attenuation, micronodules and diffuse emphysematous changes in smokers, but these changes were not found in nonsmokers (24). Pathologically, ground glass attenuation correlated with alveolitis and interstitial inflammation; parenchymal micronodules correlated with bronchiolectasis and peribronchial fibrosis, similar to those previously found in smokers (3); and emphysema exceeded the extent observed from CT analysis (1).

For $\mathrm{SBW}_{\mathrm{SM}}$ at $0 \mathrm{~s}$ of breath holding the increase in $\mathrm{D}_{\mathrm{I}}$ with smoking pack-years could be related to any one or a combination of these abnormalities. Macroscopic emphysema was unlikely to have caused the increase in $\mathrm{D}_{\mathrm{I}}$ in this group of smokers. Previous postmortem studies in smokers found no relationship between either emphysema grade, or the destructive index, and the single breath phase III slope (25) in the present study. Therefore, inflammation and fibrosis in small airways most likely accounted for the increase in $D_{I}$ in these healthy smokers in the present study. This was supported by the correlation of $D_{I}$ with $S_{n}$ in smokers (Figure 4) for $\mathrm{SBW}_{\mathrm{SM}}$ manoeuvres at $0 \mathrm{~s}$ of breath holding. Moreover, breath holding dramatically decreased $\mathrm{D}_{\mathrm{I}}$ for $\mathrm{SBW}_{\mathrm{SM}}$ manoeuvres (Figure 2), and the decrease in $\mathrm{D}_{\mathrm{I}}$ with breath holding correlated with the change in $\mathrm{S}_{\mathrm{n}}$ with breath holding (Figure 4). This observation further supported the concept that the effects of smoking on $\mathrm{D}_{\mathrm{I}}$ occurred primarily in the pulmonary parenchyma distal to the membranous bronchioles (26).

Two possible mechanisms could explain this observation. First, the decrease in $D_{I}$ and the shallower $S_{n}$ with breath holding for $\mathrm{SBW}_{\mathrm{SM}}$ may both be explained by the common effect of small airway inflammation and/or regional loss of elastic recoil on intraregional convective dependent inhomogeneity, the interaction of convection and diffusion at peripheral branch points, or both phenomena (12). Second, the breath holding effects on $D_{I}$ and $S_{n}$ may not necessarily have been causally linked to alterations in ventilation inhomogeneity as previously suggested to explain the effects of breath holding on $\mathrm{D}_{\mathrm{I}}$ in normal subjects (16). Rather, both may have been altered by time, but for different reasons. $S_{n}$ may have been steeper in smokers because of increased peripheral ventilation inhomogeneity. $\mathrm{D}_{\mathrm{I}}$ may have been increased, at least in part, by an additional effect of an exaggerated serial gradient in alveolar-capillary diffusion in smokers, such that diffusion was preferentially reduced in the proximal versus distal region of the terminal respiratory unit. Without breath holding, such a gradient in diffusion within the acinus would have created a higher carbon monoxide concentration in proximal regions that emptied early in exhalation, accounting for the higher than expected carbon monoxide concentration early in exhalation (sample 1) and the lower than expected carbon monoxide concentration later in exhalation (16). However, with breath holding this serial gradient in carbon monoxide concentration within the acinus would have rapidly decreased over time because of cardiogenic and diffusive gas mixing within the air phase of the terminal respiratory unit. Early centrilobular emphysema $(1,24)$ could have caused such a preferential decrease in diffusion in the proximal (alveolar ducts), compared with the distal (alveole), regions of the terminal respiratory units, thus exaggerating the effects of breath holding on $D_{I}$ seen in normal subjects (16).

Abnormalities in the phase III nitrogen slope in a group of healthy smokers with otherwise normal lung function have been previously reported for $\mathrm{SBW}_{\mathrm{VC}}$, but only when the smokers forcibly exhaled to RV immediately before performing the $\mathrm{SBW}_{\mathrm{VC}}$ manoeuvre (27). The proposed mechanism for this effect of smoking was that the rapid forced exhalation just preceding the $\mathrm{SBW}_{\mathrm{VC}}$ manoeuvre delayed regional emptying in peripheral regions distal to small airway inflammation and narrowing in the lungs of smokers. This reveals the presence of this disease process by transiently altering the spatial distribution ventilation by increasing specific 
ventilation in regions distal to the airway narrowing. In the present study, $\mathrm{SBW}_{\mathrm{VC}}$ manoeuvres were preceded by a deep breath, consisting of slow exhalation to RV, so that we would not have expected changes in ventilation inhomogeneity in otherwise healthy smokers due to the former mechanism (27); indeed, $\mathrm{S}_{\mathrm{n}}$ and $\mathrm{E}_{\mathrm{mix}}$ for $\mathrm{SBW}_{\mathrm{VC}}$ manoeuvres in smokers were normal. However, $\mathrm{D}_{\mathrm{I}}$ was unexpectedly increased and did not correlate with changes in $S_{n}$ in smokers suggesting that an additional factor, other than alterations in ventilation inhomogeneity, was involved. The increase in $\mathrm{D}_{\mathrm{I}}$ due to smoking for these $\mathrm{SBW}_{\mathrm{VC}}$ manoeuvres may have been due to reductions in gas diffusion in macroscopic regions of emphysema that remained ventilated, but that emptied preferentially early in expiration. This appeared unlikely because macroscopic emphysema was thought to be ventilated poorly and largely by collateral channels (28). Alternatively, and more likely, the effect of smoking on $\mathrm{D}_{\mathrm{I}}$ for these $\mathrm{SBW}_{\mathrm{VC}}$ manoeuvres may have been due to the same mechanism proposed for $\mathrm{SBW}_{\mathrm{SM}}$ manoeuvres as described above. That is, centrilobular emphysema could have caused proximal destruction of terminal respiratory units, resulting in an exaggeration of the serial gradients in diffusion from the proximal (reduced diffusion) to the distal (increased diffusion) segments of terminal respiratory units.

Previous reports found that the conventional single breath diffusing capacity for carbon monoxide $\left(\mathrm{DLCO}^{\mathrm{SB}}\right)$ (29) was reduced in smokers $(5,30)$ and correlated with macroscopic disease, as detected by CT scan techniques (31). However, in seated patients at rest $\mathrm{DLCO}^{\mathrm{SB}}$ was insensitive to the interregional nonuniformity in the distribution of emphysema that often preferentially affects the apex of the lung in smokers (5). Conventional $\mathrm{DLCO}^{\mathrm{SB}}$ testing, as distinct from the DLCO $^{\text {SB }}$-3EQ (20), was also less useful as a screening tool because the method was spuriously affected by the variations in the way the single breath test was performed (32). Interpretation of DLCO ${ }^{\mathrm{SB}}$ in smokers has also been potentially confounded by uncertainties about precise corrections of $\mathrm{DLCO}^{\mathrm{SB}}$ for carbon monoxide back pressure, carboxyhemoglobin and the binding affinity of hemoglobin (29). In the present study we corrected all measurements of $\mathrm{DLCO}^{\mathrm{SB}}-3 \mathrm{EQ}$ for the carbon monoxide back pressure by measuring the carbon monoxide in the exhaled gas during the exhalation phase of the deep breath of room air preceding each DLCO ${ }^{\mathrm{SB}}$-3EQ manoeuvre (18). The infrared carbon monoxide analyzer was sufficiently sensitive to allow measurement of background carbon monoxide in nonsmokers at levels of 0 to $70 \mathrm{ppm}$ (18). The carbon monoxide analyzer was linear in this range and was checked daily (18).

Although we did not measure carboxy-hemoglobin (29) in the smokers in this study, most of whom reported smoking in the $2 \mathrm{~h}$ before testing, it would likely have been elevated, accounting for most of the apparent reduction in $\mathrm{DLCO}^{\mathrm{SB}}-3 \mathrm{EQ}$ measured from the total sample in smokers compared with nonsmokers (22). DLCO ${ }^{\mathrm{SB}}-3 \mathrm{EQ}$ measured from the total sample in smokers would have been affected by both carbon monoxide back pressure and carboxy-hemoglobin. However, we found that $D_{I}$ required no corrections because it was not affected by increases in carboxy-hemoglobin in normal subjects (22).

The present method of measuring $\mathrm{DLCO}^{\mathrm{SB}}-3 \mathrm{EQ}$ from four sequential alveolar gas samples has a number of potential limitations. An analyzer with appropriate instrumentation and software is not currently commercially available. We employed a carbon monoxide analyzer that was modified to decrease its response time to $110 \mathrm{~ms}$ (18). The use of mass spectrometry for analysis of helium, while providing excellent signal characteristics, is too expensive for routine implementation. The manoeuvres also required instantaneous biofeedback to ensure reproducibility. This is feasible using available computer technology, and the software has been developed. In our experience, naive subjects are able to complete these manoeuvres with minimal prior coaching, but the reproducibility is less than in trained subjects (33). Finally, although this report demonstrates clear changes in smokers, the effect of smoking on $D_{I}$ is not necesarily specific. Other pathological processes that lead to small airway obstruction (34) such as bronchiolitis obliterans following lung transplant, could have similar effects.

\section{CONCLUSIONS}

We have shown that $D_{I}$ was increased in smokers in whom $\mathrm{FEV}_{1}$ was normal. The effect, which was much greater for $\mathrm{SBW}_{\mathrm{SM}}$ manoeuvres, largely disappeared with breath holding and correlated with a greater change in $S_{n}$ with breath holding, indicating that the increase in $\mathrm{D}_{\mathrm{I}}$ was caused by events occurring in the lung periphery. However, the precise structural correlates require definition. Because $D_{I}$ was also increased in smokers for $\mathrm{SBW}_{\mathrm{VC}}$ manoeuvres, in the absence of smoking-induced alterations in ventilation inhomogeneity, the effects of smoking on $\mathrm{D}_{\mathrm{I}}$ may have been due to intraregional changes in diffusion across the air-blood barrier. $\mathrm{D}_{\mathrm{I}}$ may be a more sensitive indicator of changes in the lung periphery due to smoking.

ACKNOWLEDGEMENTS: Financial support was provided by the Saskatchewan Lung Association, Saskatoon, Saskatchewan, John Cameron Moorhead Foundation, Saskatoon, Saskatchewan, and Medical Research Council of Canada, Ottawa, Ontario.

\section{REFERENCES}

1. Remy-Jardin M, Gosselin B, Becette V, Edme JL. Lung parenchymal changes secondary to cigarette smoking: Pathologic-CT correlations. Radiology 1993;186:643-51.

2. Niewoehner DE, Kleinerman J, Rice DB. Pathological changes in the peripheral airways of young cigarette smokers. N Engl J Med 1974;291:755-8

3. Cosio M, Ghezzo H, Hogg JC, et al. The relations between structural changes in small airways and pulmonary function tests. N Engl J Med 1977;298:1277-81.

4. Thurlbeck WM. Emphysema then and now. Can Respir J 1994;1:21-37.

5. Gurney JW, Jones KK, Robbins RA, et al. Regional distribution of emphysema: correlation of high-resolution CT with pulmonary function tests in unselected smokers. Radiology 1992;183:457-63.

6. Buist AS, Vollmer WM, Johnson LR, McCamant LE. Does the single-breath $\mathrm{N}_{2}$ test identify the smoker who will develop chronic airflow limitation? Am Rev Respir Dis 1988;137:293-301.

7. Engel LA, Menkes H, Wood LDH, Utz G, Joubert J, Macklem PT. Gas mixing during breath holding studied by intrapulmonary gas sampling. J Appl Physiol 1973;35:9-17. 
8. Crawford ABH, Makowska M, Paiva M, Engel LA. Convection- and diffusion-dependent ventilation maldistribution in normal subjects. J Appl Physiol 1985;59:838-46.

9. Van Muylem A, De Vuyst P, Yernault J-C, Paiva M. Inert gas single-breath washout and structural alteration of respiratory bronchioles. Am Rev Respir Dis 1992;146:1167-72.

10. Paiva M, Van Muylem A, Ravez P, Yernault JC. Inspired volume dependence of the slope of the alveolar plateau. Respir Physiol 1984;56:309-25.

11. Cotton DJ, Mink JT, Graham BL. Detection of peripheral ventilation inhomogeneity in smokers. Can Respir J 1997;4:27-33.

12. Paiva M, Engel LA. Gas mixing in the lung periphery. In: Chang HK, Paiva M, eds. Respiratory Physiology. An Analytic Approach. Lung Biology in Health and Disease, 40th edn. New York: Marcel Dekker, Inc, 1989:245-76.

13. Cotton DJ, Prabhu MB, Mink JT, Graham BL. Effects of ventilation inhomogeneity on DLCO ${ }^{\mathrm{SB}}-3 \mathrm{EQ}$ in normal subjects. J Appl Physiol 1992;73:2623-30.

14. Guy HJB, Prisk GK, Elliott AR, Deutschman RA III, West JB. Inhomogeneity of pulmonary ventilation during sustained microgravity as determined by single-breath washouts. J Appl Physiol 1994;76:1719-29.

15. Prisk GK, Guy HJB, Elliott AR, Paiva M, West JB. Ventilatory inhomogeneity determined from multiple-breath washouts during sustained microgravity on Spacelab SLS-1. J Appl Physiol 1995;78:597-607.

16. Soparkar GR, Mink JT, Graham BL, Cotton DJ. Measurement of temporal changes in DLCO ${ }^{\mathrm{SB}}$-3EQ from small alveolar samples in normal subjects. J Appl Physiol 1994;76:1494-501.

17. Crapo RO, Morris AH, Gardner RM. Reference spirometric values using techniques and equipment that meet ATS recommendations. Am Rev Respir Dis 1981;123:659-64.

18. Graham BL, Mink JT, Cotton DJ. Implementating the three-equation method of measuring single breath carbon monoxide diffusing capacity. Can Respir J 1996;3:247-57.

19. Prabhu MB, Mink JT, Graham BL, Cotton DJ. Effect of a deep breath on gas mixing and diffusion in the lung. Respir Physiol 1990;79:195-204.

20. Graham BL, Dosman JA, Cotton DJ. A theoretical analysis of the single breath diffusing capacity for carbon monoxide. IEEE Tran Biomed Engineering 1980;BME-27:221-7.

21. Graham BL, Mink JT, Cotton DJ. Effect of breath-hold time on DLco $^{\mathrm{SB}}$ in patients with airway obstruction. J Appl Physiol 1985;58:1319-25.

22. Cotton DJ, Mink JT, Graham BL. Correction of three equation diffusing capacity (DLCO ${ }^{\mathrm{SB}}$-3EQ) for carbon monoxide back pressure (Pco) with increasing carboxyhaemoglobin $(\mathrm{CO} H \mathrm{Hb})$, and demonstration that DLCO ${ }^{\mathrm{SB}}-3 \mathrm{EQ}$ from small alveolar gas samples (DI) is independent of $\mathrm{COHb}$ in normals. Am J Respir Crit Care Med 1995;151:232. (Abst)

23. Bosken CH, Wiggs BR, Pare PD, Hogg JC. Small airway dimensions in smokers with obstruction to airflow. Am Rev Respir Dis 1990;142:563-70.

24. Remy-Jardin M, Remy J, Boulenguez C, Sobaszek A, Edme J-L, Furon D. Morphologic effects of cigarette smoking on airways and pulmonary parenchyma in healthy adult volunteers: CT evaluation and correlation with pulmonary function tests. Radiology 1993;186:107-15.

25. Saito K, Cagle P, Berend N, Thurlbeck WM. The 'destructive index' in nonemphysematous and emphysematous lungs. Morphologic observations and correlation with function. Am Rev Respir Dis 1989;139:308-12.

26. Hogg W, Brunton J, Kryger M, Brown R, Macklem P. Gas diffusion across collateral channels. J Appl Physiol 1972;33:568-75.

27. Hurst TS, Graham BL, Cotton DJ. Fast vs slow exhalation before $\mathrm{O}_{2}$ inhalation alters subsequent phase III slope. J Appl Physiol 1984;56:52-6.

28. Morrell NW, Wignall BK, Biggs T, Seed WA. Collateral ventilation and gas exchange in emphysema. Am J Respir Crit Care Med 1994;150:635-41.

29. American Thoracic Society. Single-breath carbon monoxide diffusing capacity (transfer factor): Recommendations for a standard technique 1995 update. Am J Respir Crit Care Med 1995;152:2185-98.

30. Klein JS, Gamsu G, Webb WR, Golden JA, Muller NL. High-resolution CT diagnosis of emphysema in symptomatic patients with normal chest radiographs and isolated low diffusing capacity. Radiology 1992;182:817-21.

31. Gould GA, MacNee W, Mclean A, et al. CT measurements of lung density in life can quantitate distal airspace enlargement - an essential defining feature of human emphysema. Am Rev Respir Dis 1988;137:380-92.

32. Graham BL, Mink JT, Cotton DJ. Improved accuracy and precision of single-breath CO diffusing capacity measurements. J Appl Physiol 1981;51:1306-13

33. Graham BL, Mink JT, Cotton DJ. Reproducibility of three equation diffusing capacity $\left(\mathrm{DLCO}^{\mathrm{SB}}\right)$, mixing efficiency $\left(\mathrm{E}_{\mathrm{mix}}\right)$ and normalized phase three helium slope $\left(\mathrm{S}_{\mathrm{n}}\right)$ in normal subjects. Am J Respir Crit Care Med 1995;151:A786. (Abst)

34. Wright JR, Cagle P, Churg A, Colby TV, Myers J. State of the art. Diseases of small airways. Am Rev Respir Dis 1992;146:240-62. 


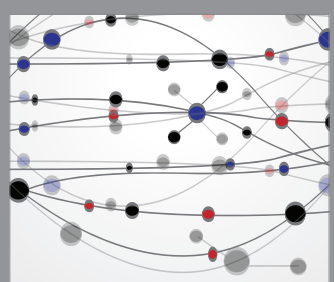

The Scientific World Journal
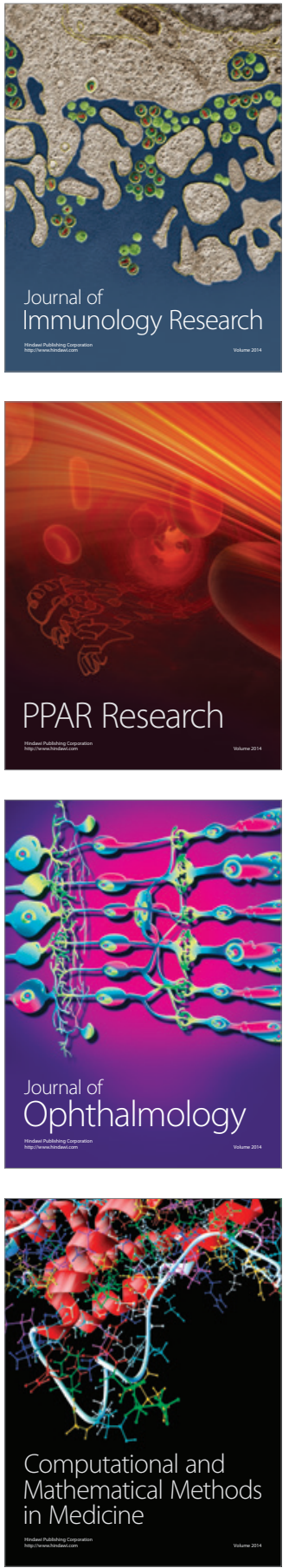

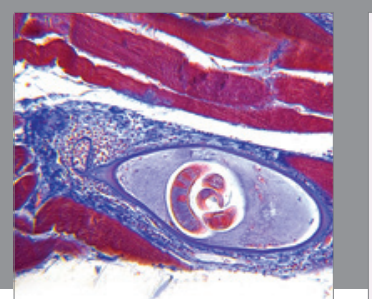

Gastroenterology Research and Practice

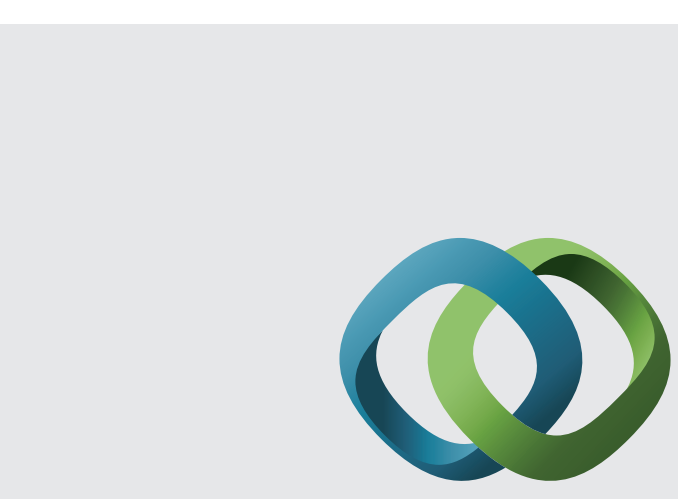

\section{Hindawi}

Submit your manuscripts at

http://www.hindawi.com
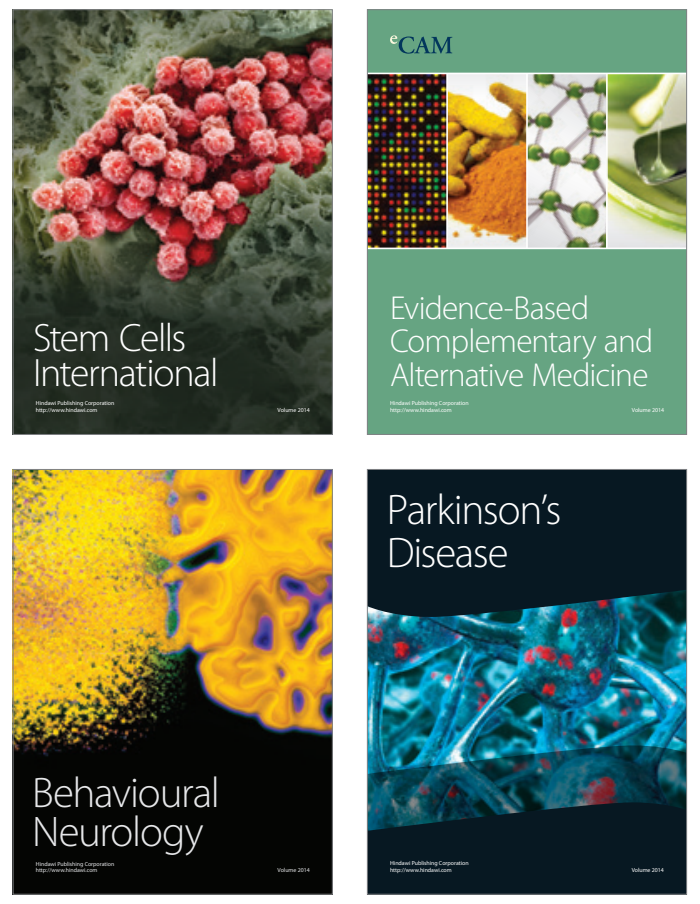
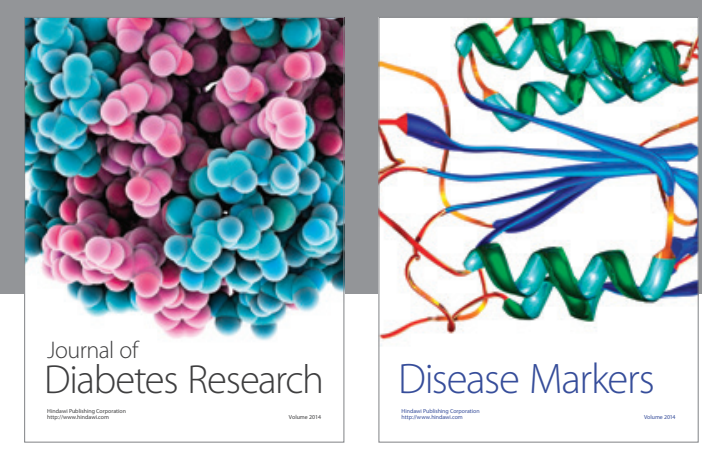

Disease Markers
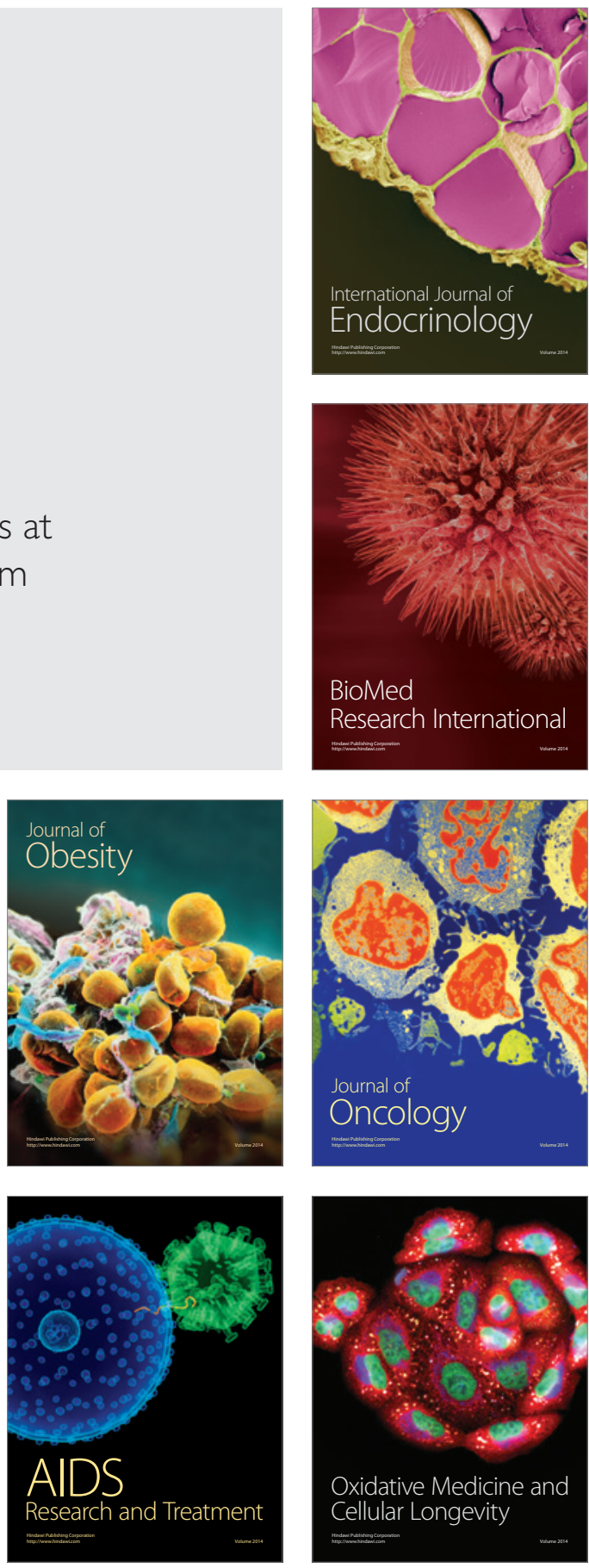